\title{
SIZE CONSTANCY JUDGMENT AND THINKING MOMENT
}

\section{SHIGERU ÖBA}

\author{
Kyoto University
}

In size constancy experiments, the standard stimulus and the comparison stimulus are usually operated. There will be a process of comparison, and results will be partly determined by Ss' personality traits. Individual differences in size constancy judgments may be attributed to the factor of thinking introversion $(\mathrm{T})$ in some degree.

Procedure. The Yatabe-Guilford personality inventory (see Psychologia, 1957, 1, 110-119) was used in this investigation. Twenty-eight $S$ s were chosen from 53 high school students. They consisted of 7 boys of higher score, 7 boys of lower score, 7 girls of higher score and 7 girls of lower score in thinking introversion. In constancy experiments the standard stimulus $(15 \mathrm{~cm}$. diameter white disc) was fixed at the distance of $8 \mathrm{~m}$. from $\mathrm{S}$; the comparison stimulus (series of 12-18 cm. daimeter discs) was presented successively at the distance of $4 \mathrm{~m}$. The steps of comparison series were $1 \mathrm{~mm}$. The method of limit was used. The laissez-faire (no instruction about the mode of judgment) set and the phenomenal set instructed by $\mathrm{E}$ were taken by Ss.

Results. Under the laissez-faire set, F for constancy judgment by the introvert-extrovert did not reach any significant level, but $F$ for sex and series of presentation were both significant at .01 level. On the basis of the standard $(150 \mathrm{~mm}$.), the boys selected a larger comparison stimulus than the standard, but the girls tended to select a smaller one than the standard. And the error of over-estimation in the boys was larger than in the girls. The mean difference between them was $9.5 \mathrm{~mm}$. Ratios of the standard stimulus (So) and the selected comparison stimulus (Sc) (Sc/So) were distributed within $.99-1.10$ in boys, and with in. $94-1.00$ in girls. Upward (from smaller to larger) presentations of comparison series gave rise to over-estimation, and judgments set down below the standard except the group of introvert boys. Downward (from larger to smaller) presentations of series caused the over-estimated judgments in all cases. And that tendencies were remarkable in boys, but the interaction in analysis of variance was not signifcant. Separate analysis of boys and girls agreed with the overall analysis. In introvert girls constancy effect seemed to be less than extrovert girls, but F did not reach 1.00 .

Although another different result was got in the condition in which Ss took the phenomenal set. That is, $M=153 \mathrm{~mm}$. of mean judgment in the introvert group, and $M=147 \mathrm{~mm}$. in the extrovert one. The difference was significant at $.01(\mathrm{df}=1$, $F=8.52$ ). The difference between both sexes became insignificant. The series effect was significant (.01). Under such a phenomenal set, the introvert girls made over-estimation, but the extrovert boys under-estimation.

Discussion. This result shows a contradictory tendency to the former studies. The cause of such a contradiction may depend upon the difference of criterion about introversion. As the thinking dimension by Yatabe has the more loading of such a trait as "meditative, over-conscientious", the instruction for phenomenal set may suggest the comparison about real objects in the introvert group, but such a reality oriented judgment of comparison might be hardly done by the instruction for phenomenal set in the extrovert group. The problem of relation between constancy and introversion might be investigated in the form of interaction concerning the preparatory set and selection of the mode of comparison.

MS. received II 7, 59.

Oba Shigeru (大羽菜 1929- ), graduated from Kyoto University, B.A. 1952: M.A. 1954; now doctor candidate. Role of the retinal and phenomenal extent between two points in the $\beta$ apparent movement. Jap. J. Psychol., 1957, 28, 28-38; Problems of set in visual space perception. Shinrigaku Hyoron (Jap. Psychol. Rev.), 1958, 2, No.1., 83-100). 